\title{
The peculiar behavior of dnaA, gyrA and gyrB temperature-sensitive mutants and their Hfr derivatives made $\operatorname{rec} A, r n h A$ or both mutants
}

\author{
Erika Coppo, ${ }^{1}$ Anna Marchese, ${ }^{1,2}$ Eugenio A. Debbia ${ }^{1}$ \\ ${ }^{I}$ C.A. Romanzi Section of Microbiology, Department of Surgical Sciences and Integrated Diagnostic (DISC), University \\ of Genoa; ${ }^{2}$ Microbiological Unit, San Martino Polyclinic Hospital, Genoa, Italy
}

\begin{abstract}
The role of the recA and rnhA mutations on the growth of different thermo-sensitive mutants at the non permissive temperature was studied. The growth of Hfr strains selected by integrative suppression in a dnaA(Ts) mutant was found strongly dependent on the RecA protein. This latter gene product was also essential for $\operatorname{gyr} A(\mathrm{Ts})$ and $\operatorname{gy} r(\mathrm{Ts}), r n h A$ double mutants for growing at $43^{\circ} \mathrm{C}$. This RecA+ dependent cell multiplication was due to the fact that all the strains studied initiated their DNA synthesis from site(s) different from the normal gene oriC. This phenomenon causes in the cell a non-stop production of the bacterial genome with concomitant disorders in the bacterial division process. It has been suggested that when the growth of the microorganism is driven by an extra-chromosomal genetic element it behaves like a transformed tumor cell. Thus the bacterial model may present many advantages for studying the mechanisms by which cells lose the control of their division process because of an infecting foreign genetic element integrated in their chromosome.
\end{abstract}

Correspondence: Eugenio A. Debbia, C.A. Romanzi Section of Microbiology, Department of Surgical Sciences and Integrated Diagnostic (DISC), University of Genoa, Largo Rosanna Benzi 10, 16132 Genoa, Italy.

Tel.: +39.010.35338136 - Fax: +39.010.3537651.

E-mail: eugenio.debbia@unige.it

Key words: Hfr, DNA gyrase mutants, recA susceptibility, DNA synthesis with and without $\mathrm{CM}$.

Contributions: the authors contributed equally.

Conflict of interest: the authors declare no potential conflict of interest.

Received for publication: 29 June 2017.

Revision received: 30 August 2017.

Accepted for publication: 1 September 2017.

CCopyright E- Coppo et al., 2017

Licensee PAGEPress, Italy

Journal of Biological Research 2017; 90:6869

doi:10.4081/jbr.2017.6869

This article is distributed under the terms of the Creative Commons Attribution Noncommercial License (by-nc 4.0) which permits any noncommercial use, distribution, and reproduction in any medium, provided the original author(s) and source are credited.

\section{Introduction}

F plasmid is a well known extrachromosomal genetic element because its structure and function have been established with a high degree of accuracy. Therefore the conjugation system as well as its stably maintenance in the bacterial host, and the control of DNA replication remains the paradigm of the behavior of this class of genetic elements. ${ }^{1-4}$ Its partition to daughter cells must be strictly governed when is replicated during the cell cycle as extra-chomosomal genetic element. F plasmid, however, can integrate into the host genome transforming the bacterial host in Hfr, in this case it is passively inherited during chromosomal replication and cell division. Hfr derivatives are also easily selected in $\operatorname{dnaA}(\mathrm{Ts})$ mutants when these strains, carrying a F plasmid, are incubated at the non-permissive temperature. The rare thermo-resistant colonies that appear derive from cells where the $\mathrm{F}$ plasmid is integrated into the host chromosome. ${ }^{5}$ In these Hfr strains at high temperature, DNA replication and cell division are under control of the $\mathrm{F}$ plasmid. Nishimura et al. (1971) and Bazzicalupo and Tocchini-Valentini $(1972)^{6,7}$ have shown that rifampin and acridine orange, at $43^{\circ} \mathrm{C}$ inhibit cell division in these strains providing evidence that the $\mathrm{F}$ replication system is sensitive to these compounds. In contrast, when the same experiments were carried out with nalidixic acid no changes were found in the MIC values of the Hfr strains at both 30 and $42^{\circ} \mathrm{C} .{ }^{8}$ These observations suggest that when DNA synthesis is driven by a plasmid the replication is dependent on the RNA polimerase (which is susceptible to rifampin) and does not require the DNA gyrase enzyme (the target of nalidixic acid). Further clues, which seem to exclude the possibility that this DNA gyrase inhibitor affects plasmid replication and conjugation, comes from experiments performed with Hfr strains selected by integrative suppression in $\operatorname{gyr} A(\mathrm{Ts})$ and $\operatorname{gyr} B(\mathrm{Ts})$ mutants. ${ }^{9,10}$ In the great majority of these Hfr strains at high temperature, the bacterial growth is not affected by rifampin and/or acridine orange and resulted totally resistant to high doses of nalidixic acid. Conversely, the ability to transfer genetic material, the generation time and the presence of elongated cells at the non permissive temperature are similar in all the Hfr strains irrespectively of the thermo-sensitive mutants they derived. Another common feature of these Hfrs selected by integrative suppression is the origin of the synthesis of the chromosome, in these microorganisms at $43^{\circ} \mathrm{C}$ the duplication of the genome appear under the control of the $\mathrm{F}$ coded enzymatic machinery instead that of the chromosome. This phenomenon indicates that all the proteins that interact with the oriC site, where the duplication of the genome initiates, which play a fundamental role in the regulation of DNA replication and cell division, are not used in these Hfr strains. This behavior is reminiscent of that of a RNase $\mathrm{H}$ defective strain ( $r n h A$ mutant). ${ }^{11,12}$ In fact, in this latter microorganism DNA is continu- 
ously synthesized because is no more regulated by the proteins that interact with oriC while the cell mass increased in a disorder way leading to filaments formation. In addition, when the $r n h$ gene is inactivated in a $\operatorname{dnaA}(\mathrm{Ts})$ mutant the strain can grow at the non-permissive temperature because it does not require the DnaA protein and it does not use the oriC for initiating DNA synthesis, but it has been found to occur at several other sites of the chromosome, designed oriK, ${ }^{11,12}$ however the growth of this latter double mutant at $43^{\circ} \mathrm{C}$ is dependent on the rec $A$ gene product. ${ }^{13}$ Following this, there are two situations where chromosome replication proceeds without the regulation of the oriC interacting enzymes: in the $r n h A$ mutants, as mentioned above, and in the Hfr strains obtained by integration of a $\mathrm{F}$ plasmid in the cited thermo-sensitive strains.

In this study the rnhA mutation was introduced in $\operatorname{gyr} A(\mathrm{Ts})$, $\operatorname{gyr} B(\mathrm{Ts})$ and, for comparison, in $\operatorname{dnaA}(\mathrm{Ts})$, to evaluate the role of this mutation in the growth of the DNA gyrase mutants. These latter double mutants were made $r e c A$ defective to study the influence of this genetic lesion on the viability of these strains cultured at $43^{\circ} \mathrm{C}$. Whether recA gene product is also required for the the growth of the Hfr selected by integrative suppression in $\operatorname{dnaA}(\mathrm{Ts})$ and thermo-sensitive DNA gyrase mutants was also studied. Finally a condition of non-stop DNA synthesis was also explored in all these latter strains.

\section{Materials and Methods}

\section{Bacterial strains}

Bacterial strains used in this study are listed in Table 1.9,10,14,15 They were previously described. ${ }^{9}, 10$ Plasmid F'lac (F'128) was one of the F' kit. F'lac plasmid carrying transposon Tn 10 that codes for tetracycline resistance was used for strain construction. J-53 and AB1157 were employed as recipient organisms depending on the experiments.

\section{Media and reagents}

The rich medium LB and the M9 minimal medium were those described by Miller. ${ }^{16}$ Media were supplemented with thymine $(25 \mathrm{mg} / \mathrm{L})$ when necessary. 5-bromouracil (5-BU), nalidixic acid (nal), coumermycin (cou), rifampin (rif), kanamycin $(\mathrm{km})$, chloramphenicol $(\mathrm{cm})$ and tetracycline (tet), as well as other chemicals were obtained from commercial sources (Sigma, Milan, Italy) and stock solutions were prepared following manufacturer's instructions.

\section{Strain construction}

Thymine-less strains were selected as suggested by Miller. ${ }^{16}$ The strain was grown in the presence of $10 \mathrm{mg} / \mathrm{L}$ of trimethoprim and $50 \mathrm{mg} / \mathrm{L}$ of thymine, after incubation to saturation, culture was diluted and plated on LB agar with thymine and then tested in M9 minimal medium with and without thymine.

Conjugation was carried out by standard methods employing $2 \times 10^{8}$ cells $/ \mathrm{mL}$ in LB broth. ${ }^{9}$ The cells were incubated for 90 minutes at permissive temperature $\left(32^{\circ} \mathrm{C}\right)$ washed in saline and plated on selective media. The P1 transduction protocol used in strain construction was described by Miller. ${ }^{16}$

\section{Growth of Hfr strains at the presence of 5-bromouracil}

Bacterial cells were cultured in M9 minimal medium supplemented with $0.2 \%$ of $\mathrm{LB}$ and $50 \mathrm{mg} / \mathrm{L}$ of 5-bromouracil (5-BU) and when necessary $2,5 \mathrm{mg} / \mathrm{L}$ of thymine. The evaluation of $\mathrm{CFU} / \mathrm{mL}$ was carried out at $0,3,6$ hours. When necessary chloramphenicol $(\mathrm{CM})$ was added $(150 \mathrm{mg} / \mathrm{L}) .{ }^{16}$

\section{Results}

Introduction of the $r n h A$ mutation in $\operatorname{dnaA(Ts)}, \operatorname{gyr} A(\mathrm{Ts})$ and $\operatorname{gyr} B(\mathrm{Ts})$ strains.

Since the requirement of the $d n a A$ gene product can be overcome by the inactivation of the RNase $\mathrm{H}$ enzyme restoring cell

Table 1. List of $E$. coli strains used in this study

\begin{tabular}{|c|c|c|}
\hline Strain & Main characteristics & Source or reference \\
\hline CTR4610 & dnaA46(Ts), leu, thy, thi & Marchese \& Debbia $(2016)^{9}$ \\
\hline db1983 & Hfr from dnaA46(Ts) & Marchese \& Debbia (2016) ${ }^{10}$ \\
\hline KNK453 & HF4704 gyrA43(Ts), thyA, polA, uvrA, phx & Marchese \& Debbia $(2016)^{9}$ \\
\hline db1873 & Hfr from gyrA43(Ts), (AO-s, Rif-s)* & Marchese \& Debbia (2016) $)^{10}$ \\
\hline $\mathrm{db} 1874$ & Hfr from gyrA43(Ts) (AO-r, Rif-r)* & Marchese \& Debbia $(2016)^{10}$ \\
\hline N4177 & galK, gyrB41(Ts), cou-r, Sm-r & Marchese \& Debbia $(2016)^{9}$ \\
\hline $\mathrm{db} 1607$ & Hfr from gyrB41(Ts) (AO-s, Rif-s)* & Marchese \& Debbia $(2016)^{10}$ \\
\hline $\mathrm{db} 1654$ & Hfr from gyrB4l(Ts) (AO-r, Rif-r)* & Marchese \& Debbia (2016) $)^{10}$ \\
\hline FB2 & rnh-1, lacY, $\mathrm{HfrH}$ & M. Berlyn ${ }^{14}$ \\
\hline CAG12148 & MG1655 tsx-247:::Tn10 & Singer et al..$^{15}$ \\
\hline FB2 (tsx-247::Tn10) & FB2 Tet-r & P1 transduction from CAG12148) \\
\hline $\mathrm{J}-53$ & proB22, metF63 & Laboratory collection \\
\hline J-53 (Flac::Tn10) & proB22, metF63, Tn10, Tet-r & Laboratory collection \\
\hline $\mathrm{HfrH}$ & Prototroph & Laboratory collection \\
\hline $\mathrm{AB} 1157$ & thr-1, leuB6, proA2, argE3, his-4, thi-1, lac Y1, galK2, rpsL31 & Laboratory collection \\
\hline AB2463 & recA13 derivative of AB1157 Tn5::recA Km-r & Laboratory collection \\
\hline
\end{tabular}

AO, acridine orange; Rif, rifampicin; Cou-r, coumermycin resistance; Sm-r, streptomycin resistance; Tet-r, tetracycline resistance; Km-r, kanamycin resistance; ${ }^{*}$ At the non-permissive temperature. 
growth at the non-permissive temperature, it was of some interest to verify if the introduction of a $r n h A$ mutation in $g y r A(\mathrm{Ts})$ and $\operatorname{gyr} B(\mathrm{Ts})$ mutants may suppress the use of such enzymes for bacterial growth. To do this three crosses were carried out employing the donor strain FB2 ( $r n h A)$ which possesses a tetracycline resistant gene at 9,5 $\mathrm{min}$ in $E$. coli chromosome. Selecting in the recipient strain for the antibiotic resistance determinant a great number of recombinants should acquire the $r n h A$ mutation. Therefore FB2 was mated with a spontaneous rifampicin resistant $d n a A(\mathrm{Ts})$ as control, and $g y r A(\mathrm{Ts})$, and $g y r B(\mathrm{Ts})$, carrying the same spontaneous antibiotic resistance. After selection of the recombinants in the appropriate medium, colonies were purified and tested for temperature resistance. As reported in Table 2, about the same number of recombinants originated from the three crosses were able to grow at $43^{\circ} \mathrm{C}$. Therefore the $r n h A$ gene phenotypically suppress the lethal effect of the temperature, as expected, in $\operatorname{dna} A(\mathrm{Ts})$, and also in $\operatorname{gyr} A(\mathrm{Ts})$ and $\operatorname{gyr} B(\mathrm{Ts})$. The results obtained indicate that inactivation of the RNase H enzyme, abolishes the requirement of a functional DNA gyrase activity. Then a strain begins DNA synthesis from site(s) different from oriC needs neither DnaA protein nor DNA gyrase enzyme.

\section{Transduction of rec $A$ gene in $\mathbf{r n h} A$ derivatives of mutants in $\operatorname{dna} A(\mathrm{Ts}), \operatorname{gyr} A$ (Ts) and $g y r B(\mathrm{Ts})$ mutants}

Further clues of the fact that the thermo-resistant $r n h A$ derivatives of $g y r A$ (Ts) and $g y r B(\mathrm{Ts})$ can grow at $43^{\circ} \mathrm{C}$ because RNase
$\mathrm{H}$ is inactivated in these strains might be come from the introduction of the rec $A$ gene in these mutants. To do this, P1 phage grown on $\mathrm{AB} 2463$ was used to infect $\operatorname{dnaA}(\mathrm{Ts}) r n h A$, gyrA(Ts) $r n h A$ and $g y r B(\mathrm{Ts}), r n h A$ double mutants. In order to confirm the presence of the recA mutation, after selection for kanamycin resistance the total transductants of 3 separate experiments were tested for susceptibility to ultraviolet light (UV), the phenotype of the recombination-negative strains. As reported in Table 3, among the UV-susceptible strains found, about the $80 \%$ of the isolates showed a temperature susceptibility phenotype, regardless the double mutant they originate. These results showed for all these strains a very similar behavior, and suggest the requirement of the activity of the $\operatorname{rec} A$ gene product for growth at the non permissive temperature in these strains.

\section{Selection of $r e c A$ mutants in $\mathrm{Hfr}$ derivatives of $\operatorname{dna} A(\mathrm{Ts}), \operatorname{gyr} A(\mathrm{Ts})$ and $g y r B(\mathrm{Ts})$}

The results obtained in the above experiments suggest many analogies between the behavior of $\operatorname{dnaA}(\mathrm{Ts})$ and DNA gyrase temperature-sensitive mutants. It appeared of some interest to verify a property never studied in all these strains, especially in the Hfr strains selected by F'lac integrative suppression. In these strains, in particular, the origin of DNA synthesis other than oriC site, render all the microrganisms dependent on the functional RecA protein to growth. Following this, the $r e c A$ gene was transduced in the Hfr derivatives of $\operatorname{dnaA}(\mathrm{Ts}), \operatorname{gyr} A(\mathrm{Ts})$ and $g y r B(\mathrm{Ts})$.

Table 2. Construction of $r n h$ - derivatives of $\operatorname{dnaA(Ts)}$, $g y r A(\mathrm{Ts})$ and $g y r B(\mathrm{Ts})$ mutants.

\begin{tabular}{lccc} 
Cross & $N^{\circ}$ recombinants tested & $N^{\circ}$ of thermo-resistant strains found & Percentage \\
FB2 X dnaA(ts) & 50 & 19 & 38 \\
\hline FB2 X gyrA(Ts) & 50 & 16 & 32 \\
\hline FB2 X gyrB(Ts) & 50 & 13 & 26 \\
\hline
\end{tabular}

Average of 3 separate experiments.

Table 3. Transduction of $r e c A$ gene into $r n h$ - derivatives of $d n a A(\mathrm{Ts}), \operatorname{gyr} A(\mathrm{Ts})$ and $g y r B(\mathrm{Ts})$ mutants.

\begin{tabular}{|c|c|c|c|c|c|}
\hline Strain & $\begin{array}{c}\mathrm{N}^{\circ} \text { of transductants } \\
\text { studied }^{\mathrm{a}}\end{array}$ & UVs & Percentage & $\begin{array}{c}\mathrm{N}^{\circ} \text { of } \\
\text { temperature-susceptible }\end{array}$ & Percentage \\
\hline $\operatorname{dnaA}(\mathrm{Ts}), \mathrm{rnh}$ & 152 & 144 & 93 & 124 & 86 \\
\hline gyrA(Ts), rnh & 150 & 142 & 89 & 110 & 77 \\
\hline gyrB(Ts), rnh & 178 & 164 & 92 & 134 & 82 \\
\hline
\end{tabular}

aCumulative data of 3 separate experiments; Selection for Km-r; bamong UVs transductants.

Table 4. Transduction of $\operatorname{rec} A$ gene into $\mathrm{Hfr}$ derivatives of $\operatorname{dna} A(\mathrm{Ts}), \operatorname{gyr} A(\mathrm{Ts})$ and $\operatorname{gyr} B(\mathrm{Ts})$.

\begin{tabular}{|c|c|c|c|}
\hline Hfr derivatives & $\mathrm{N}^{\circ}$ tested ${ }^{*}$ & $\begin{array}{l}\text { Susceptibility to } \\
43^{\circ} \mathrm{C}\end{array}$ & Frequency \\
\hline db1983 dnaA(Ts) & 50 & 28 & 56 \\
\hline db1873 gyrA(Ts) & 50 & 22 & 44 \\
\hline db1874 gyrA(Ts) & 50 & 26 & 52 \\
\hline db1607 gyrB(Ts) & 50 & 16 & 32 \\
\hline db1654 gyrB(Ts) & 50 & 21 & 42 \\
\hline
\end{tabular}

*Strains selected among those susceptible to UV light. 
As reported in Table 4, from 32 to $56 \%$ of the UV susceptible isolates demonstrated a growth inhibition at the non-permissive temperature.

\section{Growth of Hfr strains at the presence of 5-bromouracil, a base analogue}

Considering all the data obtained here, the Hfr derivatives of the thermo-sensitive mutants present many analogies with RNAse $\mathrm{H}$ - defective mutant, in particular, as mentioned above, the initiation of new DNA synthesis starts from sites other than oriC. This unique situation renders possible in this mutant a continue DNA replication in the absence of normally required protein synthesis. Therefore it is possible to verify this assumption using 5-BU, a base analogue that is incorporated into the DNA during the synthesis of the genome in substitution of thymine. This incorporation is lethal for the cells because it induce alteration in the sequence of the DNA leading to mutations and errors in gene expression. The bacteria were then cultured in the presence of this mutagen for 6 hours at the non permissive temperature with and without $\mathrm{cm}$. The Hfr studied included strains both acridine orange and rifampin susceptible or resistant at the non permissive temperature. The results obtained are depicted in Figure 1. The HfrH used as control stop to grow and to incorporate 5-BU when $\mathrm{cm}$ was added to the culture. On the contrary all the Hfr derivatives of thermo-sensitive mutants show a certain degree of lethality under the same experimental conditions.

\section{Discussion and Conclusions}

The results obtained in this work can be resumed as follows: a) the introduction of the $r n h A$ gene in $\operatorname{dnaA(Ts)}$ for control and in $g y r A(\mathrm{Ts})$ and $\operatorname{gyr} B(\mathrm{Ts})$ restores the growth of these strains at the non-permissive temperature; b) the growth of these double mutants at $43^{\circ} \mathrm{C}$ is dependent on the rec $A+$ gene product c) the growth of the Hfr strains obtained by integrative suppression of $\mathrm{F}$ plasmid in $\operatorname{dna} A(\mathrm{Ts})$ and in $\operatorname{gyr} A(\mathrm{Ts})$ and $\operatorname{gyr} B(\mathrm{Ts})$ at $43^{\circ} \mathrm{C}$ is abolished by the introduction of the recA-defective gene; d) the 5 -BU is lethal in these latter strains at the non permissive temperature even if chloramphenicol is added. The present findings suggest some observations. The E. coli rnhA mutants lacking RNase $\mathrm{H}$ activity are capable of $r e c A+$ depending DNA synthesis which is called stable DNA replication ${ }^{11-13}$. In a $r n h A$, dnaA(Ts) double mutant at $43^{\circ} \mathrm{C}$ initiation of DNA synthesis at the oriC site is not used and the reproductive DNA replication cycle begins from site(s) spread along the chromosome named oriK. The same behavior was observed here in the $g y r A$ (Ts) and $g y r B(\mathrm{Ts}), r n h A$ double mutants which demonstrated the requirement of the RecA protein for growth at the non permissive temperature. In this context, the fact that the multiplication of the Hfr strains selected by $\mathrm{F}$ integration in $\operatorname{dnaA}(\mathrm{Ts})$ mutant is dependent on the $\operatorname{rec} A$ gene product, is another interesting finding achieved in this work. In this strain, in fact, genetic evidence demonstrates that the F plasmid drives DNA synthesis and cell growth. The susceptibility to rifampin supports the first point, and the recA+ dependent bacterial division suggests that DNA synthesis initiates from site other than oriC Therefore by a genetic point of view in these $\mathrm{Hfr}$ strains there is a stable DNA replication. Studies from this laboratory demonstrated the integration of $\mathrm{F}$ plasmid in $g y r A(\mathrm{Ts})$ and gyrB(Ts) background lead to the formation of Hfr strains with concomitant ability of these derivatives to survive at $43^{\circ} \mathrm{C} .^{9,17}$
Taken together these observations indicate that in strains where proteins such as DnaA, GyrA, and GyrB, which interact with ori $C$, are inactivated by the temperature, the growth of the bacteria can be restored by the introduction of a $r n h A$ gene or by integration of a $\mathrm{F}$ plasmid into chromosome. Both phenomena have in common that oriC is no more used by the cell to initiate DNA replication. Although the above data are preliminary observations about a mechanism by which bacteria can survive under restrictive conditions some additive considerations can be done. The growth of a bacterial cell is a perfect equilibrium among a large number of metabolic reactions. DNA replication initiated to a fixed site because many enzymes interact with this locus only when the cell needs to balance the genome duplication with that of the other components of the cell. If DNA and macromolecular production are not coupled to each other, bacteria may survive, but the cell division process is no more under control. For example, in strains where DNA synthesis originate from site(s) other than $\mathrm{oriC}$ the genome is continuously produced irrespectively of the mass content of the cell, then bacteria tends to form filaments and divide in cells of various size. In considering the role of the rec $A$ gene functions in the growth of the above mutants at nonpermissive temperature, further observations have to be added. It is know that in a certain bacterial population spontaneous mutants can arise, with different incidence. This phenomenon reflects the introduction of errors during DNA synthesis. Many of these mistakes are repaired by induction of the recA gene depending functions and, during this period, bacteria are unable to divide. ${ }^{18,19}$ Thus, strains unable to induce a proficient DNA repair system, such as lexA/recA-defective mutants, tend to die immediately if the emerging mutations involve essential genes. A recent report of Dimude et al. ${ }^{20}$ underlined that when chromosome duplication starts from oriC it moves in two opposite directions until ter $A$ site. In the same time many genes are transcribed in the same directions avoiding any collisions between the two synthesis. In bacterial cells where the initiation of DNA duplication is other than oriC a significant number of the resulting forks proceed in the opposite direction from that normally dictated by the replication arrangement, leading to more frequent collisions with ongoing transcription complexes. These replication-transcription encounters might be responsible of a high number of error in DNA replication, and in the case of an impaired SOS repair mechanism, the viability of the bacteria is compromised, as occurs in the strains studied here. In trying to extrapolate these considerations, it is a general assumption that when an extrachromosomal genetic element, plasmid or bacteriophage, is inserted onto genome this is passively duplicate as any other segment of the DNA. If the phage occasionally expresses some genes this lead to virus production and cell death. On the contrary there are no studies about the identification of bacteria that grow under plasmid control. For example among a population of wild-type Hfr bacteria (excluding thus the mutants studied here) may be of some interest to discover a strain where the integrate plasmid presents some of their genes activated and so the life of the cell depend on these genetic information. Conversely, it is known that some animal viruses (oncogenic viruses) when infected the eukaryotic cell integrate its genome into cellular DNA leading to a continuous division of the cell (tumor cell). Although the above phenomenon is not fully elucidated it is a general idea that this occurs by the same mechanism by which bacteriophages lysogenise bacteria. Therefore any extrachromosomal genetic element which transforms bacteria may be a simple model to study the development of tumor cells. 
B

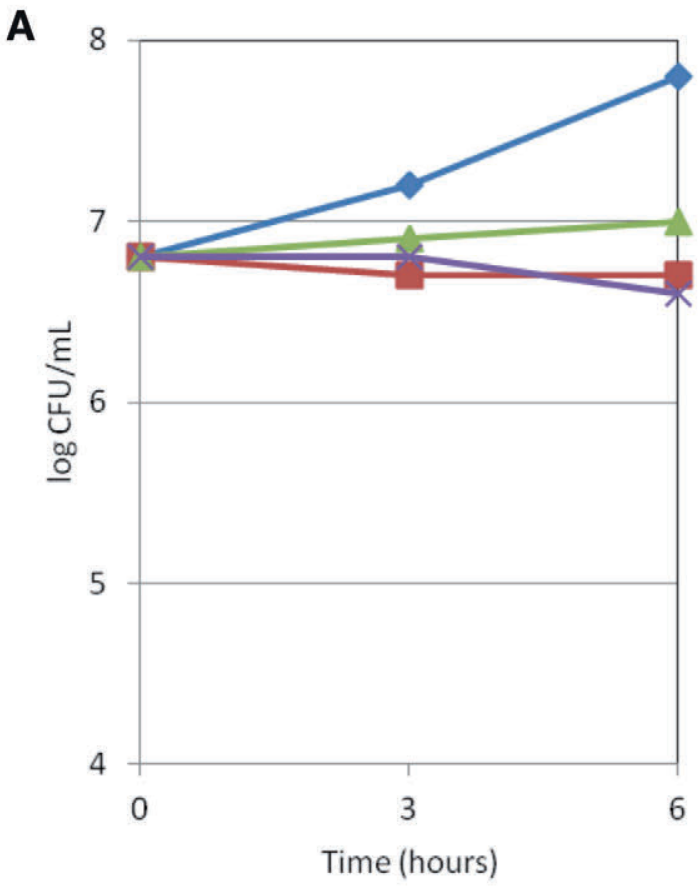

$\longrightarrow$ Control $\longrightarrow \mathrm{CM} \longrightarrow 5-\mathrm{BU} \longrightarrow \mathrm{CM}+5-\mathrm{BU}$

C

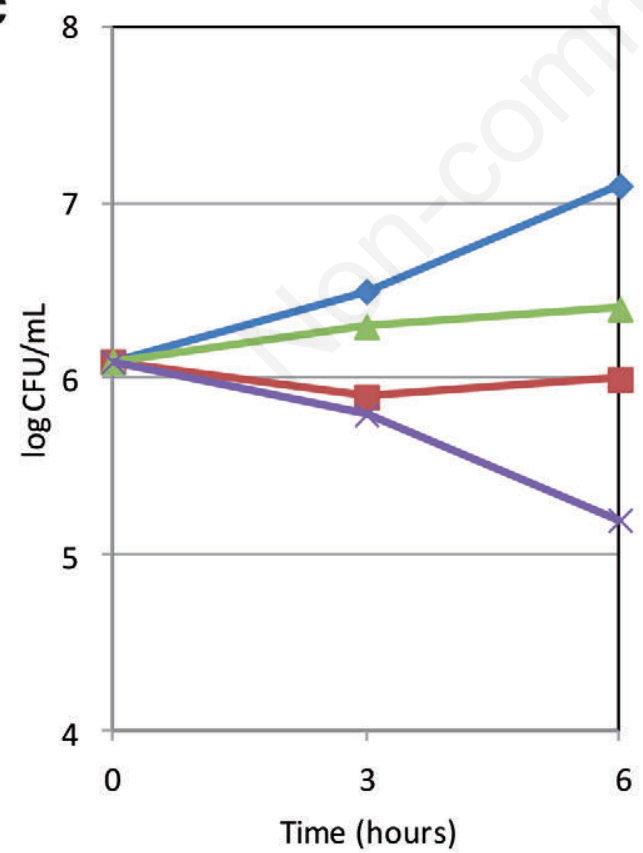

$\leadsto$ Control $-\mathrm{CM}=5-\mathrm{BU} \leadsto \mathrm{CM}+5-\mathrm{BU}$

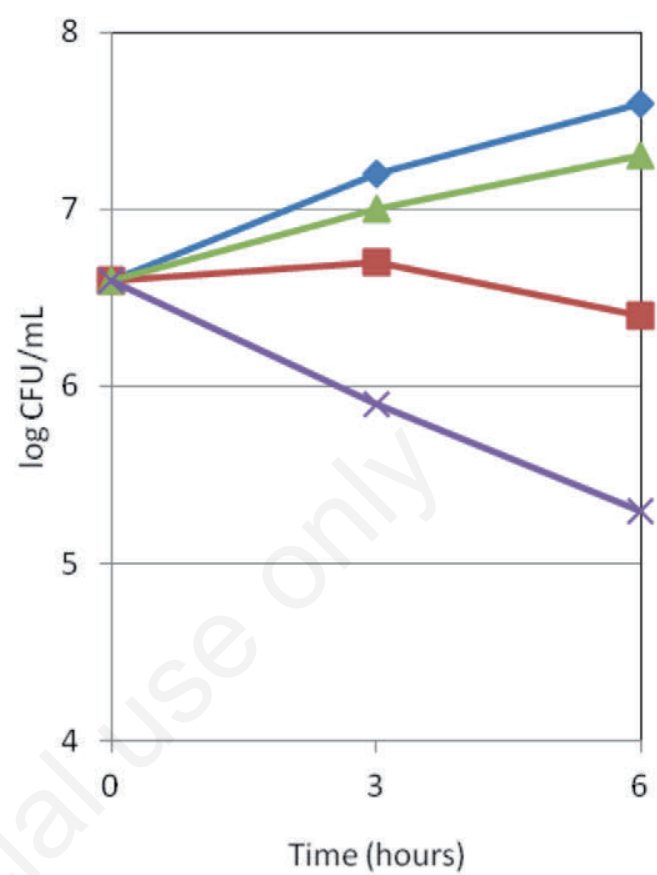

$\leadsto$ Control $-\mathrm{CM} \rightleftharpoons \mathrm{L}-\mathrm{BU} \rightleftharpoons \mathrm{CM}+5-\mathrm{BU}$

D

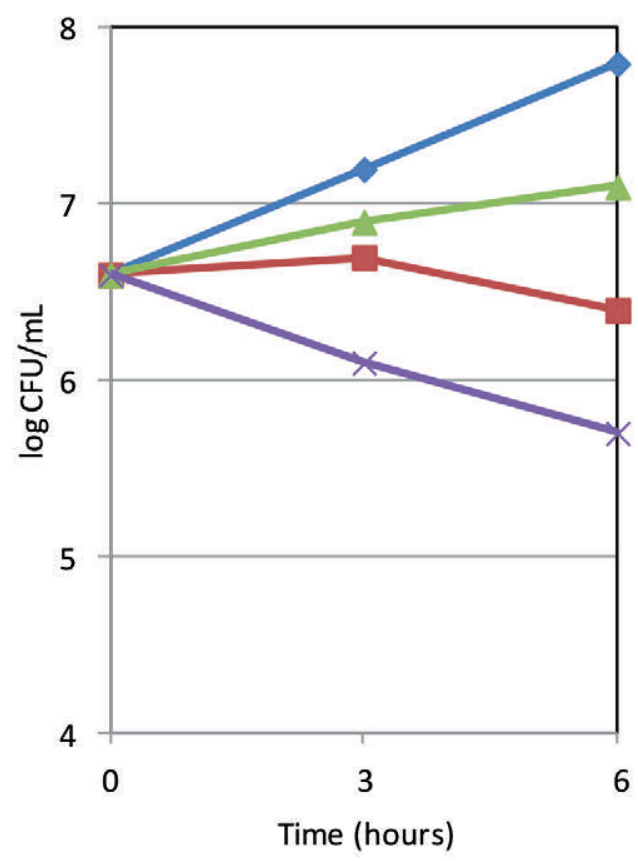

$\longrightarrow$ Control $\longrightarrow \mathrm{CM}=5-\mathrm{BU} \rightleftharpoons \mathrm{CM}+5-\mathrm{BU}$

Figure 1. Hfr derivatives and the control incubated at restrictive temperature $\left(43^{\circ} \mathrm{C}\right)$, in the presence of chloramphenicol $(50 \mathrm{mg} / \mathrm{L})$ $\mathrm{CM}$, or 5-bromouracil ( $50 \mathrm{mg} / \mathrm{L}) 5-\mathrm{BU}$, or both. A) $\mathrm{HfrH}$; B) dnaA(Ts); C) gyrA(Ts); D) gyrB(Ts). The best of at least 6 separate experiments are plotted here. 


\section{References}

1. Lane HED. Replication and incompatibility of $\mathrm{F}$ and plasmids in the IncFI group. Plasmid 1981;5:100-26.

2. Willetts N, Skurray R. Structure and function of the F factor and mechanism of conjugation. In: Ingraham JL, Brooks Low L, Magasanik B, et al., eds. Escherichia coli and Salmonella typhimurium: cellular and molecular biology. Vol.2, Washington D.C: American Society for Microbiology; 1987. pp 1110-1132.

3. Johnson CM, Grossma AD. Integrative and conjugative elements (ICEs): what they do and how they work. Ann Rev Genet 2015;49:577-601.

4. Fernandez-Lopez R, deToro M, Moncalian G, et al. Comparative genomics of the conjugation region of F-like plasmids. Five shades of F. Front Mol Biosci 2016;3:71.

5. McMacken R, Silver L, Georgopoulos C. DNA replication. In: Ingraham JL, Brooks Low L, Magasanik B, et al., eds. Escherichia coli and Salmonella typhimurium: cellular and molecular biology. Vol.1, Washington D.C: American Society for Microbiology; 1987. pp 565-612.

6. Nishimura Y, Caro L, Berg CM et al. Chromosome replication in Escherichia coli, IV. Control of chromosome replication and cell division by an integrated episome. J Mol Biol 1971;55:441-56.

7. Bazzicalupo P, Tocchini-Valentini GP. Curing of an Escherichia coli episome by rifampicin. Proc Natl Acad Sci USA 1972;69:298-300.

8. Debbia EA. Filamentation promotes F'lac loss in Escherichia coli K12. J Gen Microbiol 1992;138:2083-91

9. Marchese A, Debbia EA. The role of gyrA, gyrB, and dnaA functions in bacterial conjugation. Ann Microbiol 2016;66:223-8.
10. Debbia EA, Marchese A. Characterization of Hfr strains selected by integrative suppression of F'lac in dnaA, gyrA and gyrB temperature sensitive mutants. J Biol Res 2017;90;6595.

11. Kogoma, T. RNase H-defective mutants of Escherichia coli. J Bacteriol 1986;166:361-3.

12. Kogoma T. Stable DNA replication: interplay between DNA replication, homologous recombination, and transcription. Microb Mol Biol Rev 1997;61:212-38.

13. Kogoma T, Skarstad K, Boye E, et al. RecA protein acts at the initiation of stable DNA replication in rnh mutants of Escherichia coli K-12. J Bacteriol 1985;163:439.44.

14. Berlyn MKB. Linkage map of Escherichia coli K12, edition 10: the traditional map. Microbiol Mol Biol Rev 1998;62:814-94.

15. Singer M, Baker TA, Schnitzler G, et al. A collection of strains containing genetically linked alternating antibiotic resistance elements for genetic mapping of Escherichia coli. Microbiol Rev 1989;53:1-24.

16. Miller JH, ed. Experiments in molecular genetics. New York: Cold Spring Harbor; 1972.

17. Debbia EA, Marchese A, Saverino D, et al. F'lac integrative suppression in $\operatorname{gyrB}(\mathrm{Ts})$ mutant. 93 ${ }^{\text {rd }}$ General Meeting ASM Abstr. H40. Atlanta, USA; 1993.

18. Walker GC. The SOS response of Escherichia coli. In: Ingraham JL, Brooks Low L, Magasanik B, et al., eds. Escherichia coli and Salmonella typhimurium: cellular and molecular biology. Vol.2, Washington D.C: American Society for Microbiology; 1987. pp 1400-16.

19. Debbia EA, Roveta S, Schito AM, et al. Antibiotic persistence: the role of spontaneous DNA repair response. Microb Drug Resist 2001;7:335-42.

20. Dimude JU, Stockum A, Midgley-Smith SL, et al. The consequences of replicating in the wrong orientation: bacterial chromosome duplication without an active replication origin. MBio 2015;6:e01294-15. 